\title{
Composites for Bone Surgery Based on Micro- and Nanocarbons
}

\author{
E. Stodolak, A. Fraczek-Szczypta*, M. Blazewicz and S. Blazewicz \\ Faculty of Materials Science and Ceramics, Department of Biomaterials \\ AGH - University of Science and Technology, al. Mickiewicza 30, 30-059 Kraków, Poland
}

\begin{abstract}
In this work capabilities of polymer composites modified with carbon materials for application in the bone surgery were compared. The composite materials were produced from synthetic polymer PTFE-PVDF-PP modified with a carbon phase such as: short carbon fibres, carbon nanotubes and carbon fabrics. Determination of mechanical properties of the composite materials indicated that the carbon phase improves strength and Young's modulus of the composite. Moreover, the mechanical parameters can be controlled by the form and amount of the carbon phase introduced into the polymer matrix. Both the fibres and the carbon nanotubes influenced wettability and surface energy of the composites. Also topography of the materials surface was altered, and its roughness was optimal for bone cells (profilometry). Osteoblasts contacted with the polymer-carbon composites showed increased viability comparing with the ones contacting with the pure polymer foil (viability, and cells proliferation: MTT method, concentration of bone protein: viniculine and $\beta$-actine). Results of the investigations indicated that the composite materials containing carbon phases are potential materials for repairing of bone tissue damages.
\end{abstract}

PACS numbers: 81.05.Qk, 81.05.uj, 87.85.jj, 87.85.jc, 87.17.Ee

\section{Introduction}

Nowadays composite materials more frequently replace typical polymer, ceramic and metallic materials in medical applications. A composite material which is readily used in bone surgery is polymers enriched with various forms of carbon. Addition of a carbon phase in the form of fabrics, fibres or nanometric particles such as nanotubes or fullerenes into a polymer matrix influences mechanical, physicochemical and biological parameters of the material [1-4]. Introduction of proper amounts of carbon fibres or particles into the polymer matrix enables to modify in a controlled way the material's properties such as: strength, modulus of elasticity and mechanical anisotropy in order to match them with the implantation place $[3,5]$. Distribution of the modifying phase within polymer matrix affects both the composite strength and its surface energy, and also the microstructure of the material.

Literature shows that both carbon fibres and carbon nanotubes may act osteoconductively on an implant material. The presence of carbon fibres simulating collagen fibres facilitates adhesion and proliferation of cells on the material's surface $[6,7]$. The presence of carbon nanotubes enhances bioactivity of the polymer matrix by acceleration of nucleation of apatite, and simultaneously improves wettability and surface free energy of the material which makes it more suitable for bone cells $[8,9]$.

Implants applied in guided tissue regeneration (GTR)

* corresponding author; e-mail: afraczek@agh.edu.pl technique are particular types of composite materials. Controlled regeneration of bone tissue (GBR) is an effective technique of healing bone deficits, in particular deficits in submaxilla bone [10]. The principle of the method is based on creation of optimal conditions for regeneration of bone tissue and may be also applied in places, where a fast restoration of bone tissue is required [11].

Composites made of a biostable polymer matrix modified with carbon fibers were the object of this study. The aim of the work was the analysis of possibilities of application of composites for bone surgery based on microand nanocarbons which can be used as constructive elements (composites with carbon fabric 1D, 2D) [3, 5], as a composite membrane for GBR/GTR technique (composite with short carbon fibres (SCF) and carbon nanotubes $(\mathrm{CNT}))[6,10]$, as composites for tissue engineering which can stimulate a cellular response [12]. Dispersion of SCF and $\mathrm{CNT}$ in the polymer matrix changes cell response to implant in comparison to the pure polymer. Carbon nanotubes, submicron carbon fibers can enhance cells adhesion, multiplication, and function. They can play a significant role in biomaterials and tissue engineering [13].

This article presents selected issues related to different forms of carbon phases present in polymer-matrix composites used for bone tissue regeneration. Some of them modify mechanical properties of the material in order to match them with the ones of a bone, while others influence physico-chemical properties of the surface and make it more suitable for bone cells to grow and regenerate damaged tissue. 


\section{Materials and methods}

The composite components used to modify a terpolymer PTFE-PVDF-PP (poly(tetrafluoroethylene-co-vinyldifluoride-co-propylene) (Sigma-Aldrich) were micro- and nanocarbons. As carbon microfillers, a carbon fabric (CFb, 2D, Torayca, Japan) and SCF were used. The carbon fibers were produced from PAN precursor (Mavilon Hungary) by its carbonisation at $1400^{\circ} \mathrm{C}$. Three-fraction microfiller was prepared by grinding of the short carbon fibres in a rotating mill. The first submicron fraction consisted of fibers of diameter $\approx 7 \mu \mathrm{m}$ and length $\approx 1.2 \mathrm{~mm}$ (about $80 \%$ of the population); second fraction had size $\approx 5.5 \mu \mathrm{m}$ (about $12 \%$ of the population) and the last fraction was smaller than $150 \mathrm{~nm}$ (about $8 \%$ of the population). As carbon nanofillers single-walled carbon nanotubes (SWCNT) were used (NanoCraft Inc Renton, USA). SWCNTs were 2 to $3 \mathrm{~nm}$ in diameter and 30 to $50 \mathrm{~nm}$ in length. Moreover, the carbon fabric with regular rowing array ( $\mathrm{CFb}-\mathrm{r})$ was used.

Composites matrix consisted of PTFE-PVDF-PP terpolymer with density of $1.6 \mathrm{~g} / \mathrm{cm}^{3}$. Polymer solution with 1:10 ratio was obtained by dissolving of PTFE-PVDF-PP in acetone. The concentration of the carbon nanotubes and short carbon fibers was $4 \mathrm{wt} \%$. The obtained polymer solutions were mixed with SWCNT and SCF by means of sonicator for $10 \mathrm{~min}$. This way two kinds of samples were prepared:

- $\mathrm{SF} 4-4$ wt\% SWCNT/terpolymer;

- $\mathrm{FF} 4$ - 4 wt\% SCF/terpolymer.

Amount of a carbon phase in the case of the fabric was $\approx 63 \mathrm{wt} \%$. Part of the carbon fabric was covered with the polymer solution and left to evaporate the solvent. One kind of a composite containing the carbon fabric was produced:

\section{- CF63 - CFb-r/terpolymer.}

A pure terpolymer foil was used as a reference material.

The contact angle was measured by the sessile drop method (DSA 10 Mk2, Kruss, Germany). The surface energy of composite samples was investigated by the Owens-Wendta method. Roughness of the composite surface was determined by the surface profilometry technique (Hommel Tester T1500). Mechanical properties of the composites were measured using a universal testing machine (Zwick 1435, Germany).

The carbon-polymer composites were sterilized by the $\mathrm{H}_{2} \mathrm{O}_{2}$-plasma method. All materials were seeded with human osteoblast-like MG 63 cells (European Collection of Cell Cultures, Salisbury, UK) incubated for 1 to 7 days in $10 \%$ fetal bovine serum at $37^{\circ} \mathrm{C}$. The cells proliferation was detached with a trypsin-EDTA solution in phosphate buffered saline (PBS). The viability of cells in contact with the composite samples was measured using MTT method. In addition, molecules participating in the process of cell adhesion and spreading (i.e., integrin-associated proteins vinculin and $\beta$-actin, an important component of the cytoplasmatic cytoskeleton) were visualized by immunofluorescence staining and their concentration was evaluated semiquantitatively by the enzyme-linked immunosorbent assay (ELISA).

\section{Results and discussion}

The carbon fillers introduced into the synthetic polymer matrix enhance mechanical properties of the composites. The conducted tensile tests proved that each kind of the carbon phase increased tensile strength of the composites (Fig. 1). $4 \mathrm{wt} \%$ amount of SCF, in which both submicrometric and nanometric fibers fraction existed, led to twofold increase of tensile strength of the composite.

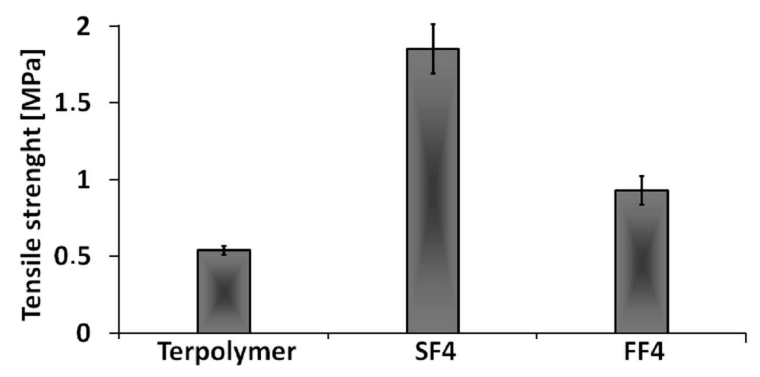

Fig. 1. Tensile strength of the polymer and the composite samples.

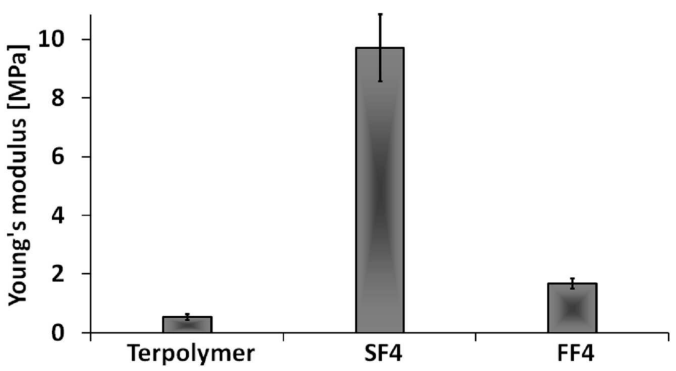

Fig. 2. Young's modulus of the polymer and the composite samples.

According to the conventional composites theory the applied fraction of the fibrous phase e.g. $4 \mathrm{wt} \%$ should deteriorate mechanical properties of a composite and the carbon fibres should act as defects. Nanometric fraction of fibers (the fraction smaller than $150 \mathrm{~nm}$ ) interacted with the polymer matrix leading not only to increased strength comparing to the pure this sample (Figs. 2 and 3). The single-wall carbon nanotubes had the similar influence on the polymer matrix, which increased both tensile strength and Young's modulus (Figs. 1 and 2). Tensile strength and Young's modulus of composites containing $4 \mathrm{wt} \%$ of SWCNT (SF4) was about 3.5 times and about 18 times higher, respectively, than in the case of 


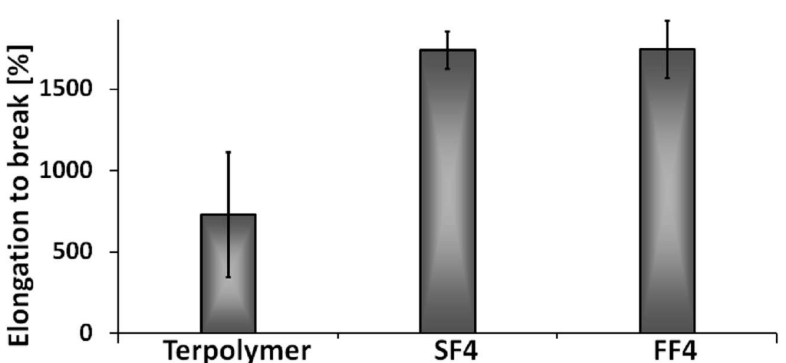

Fig. 3. Elongation to break of the polymer and the composite samples.

the pure polymer foil. The change of mechanical properties of such systems depends mainly on dispersion state of SWCNTs in a polymer matrix. Better dispersion leads to higher tensile strength and Young's modulus of the material. High deformability of a material containing SCFs and SWCNTs indicates that the presence of nanoparticles plays an important role during deformation of the material (Fig. 3). This behaviour could be explained by straightening of polymer chains during tension of composites containing SWCNT related to an ability of the nanotubes to embed between the main chains of the polymer, and also because of the formation of short-range interactions on the CNTs/polymer matrix interface [14].

Mechanical tests performed on conventional composites based on the carbon fabric indicated that increase of the material's strength may be controlled in a wide range by altering the amount of a carbon fibrous phase and its arrangement in the polymer matrix. In the case of $2 \mathrm{D}$ fabric (CF63), tensile stresses are transmitted only by fibres which are parallel to the applied force. Such fabric acted then as 1D system, and tensile strength $\left(R_{\mathrm{m}}\right)$ of the composite increased to $385 \mathrm{MPa}$, while $R_{\mathrm{m}}$ of the pure polymer foil was about $0.5 \mathrm{MPa}$. The results confirmed usability of the composite materials based on carbon additives (fibres, nanotubes, fabrics) as materials with mechanical properties similar to bone tissue. Such materials may perform structural and filling functions of the bone tissue losses.

The choice of PTFE-PVDF-PP polymer was based on its piezoelectric properties. Bone also exhibits piezoelectric effect, and moreover natural tissues contain water, which is a good electric conductor. Properties of materials destined for bone surgery are modelled to mimic the properties of the natural tissues [15-17]. In composites in which as a modifying phase carbon fibres or nanotubes were applied their electric conductivity was used. The pure polymer (a composite matrix) is an electric insulator $(\rho=9.78 \mathrm{k} \Omega \mathrm{m})$, but introduction of a small amount of a carbon phase changes resistance of the material (Table I).

The lowest resistivity was observed for composites containing $4 \mathrm{wt} \%$ of SWCNT (SF4). In this case and in the case of composite containing $4 \mathrm{wt} \%$ of SFC (FF4) the crucial parameter influencing their electrical characteristics is dispersion of fibrous phase which enables formation of a TABLE I

Resistivity of polymer composites containing carbon fibers and carbon nanotubes.

\begin{tabular}{c|c|c|c|c}
\hline \hline & Terpolymer & SF4 & FF4 & CF63 \\
\hline $\begin{array}{c}\text { Resistivity } \\
{[\mathrm{k} \Omega \mathrm{m}]}\end{array}$ & $9.78 \pm 0.98$ & $0.07 \pm 0.01$ & $0.25 \pm 0.03$ & $1.96 \pm 0.20$
\end{tabular}

system of interconnected fibers/nanoparticles (so called percolation path) responsible for conduction of electric current [18].

If the materials are destined for application as materials guiding accelerated regeneration of bone losses, then their suitability should be evaluated on the basis of physico-chemical properties of their surface. Topography, wettability and free surface energy of the carbon composites indicate that the carbon phase may alter the surface of such materials. These are important factors determining faster adhesion and proliferation of bone tissue cells and connective tissue cells [19-21]. The applied polymer (PTFE-PVDF-PP) is characterised by highly hydrophobic surface which hinders seating of proteins and improves adhesion of bone cells.

Carbon phases influenced hydrophobity of the composite surface only in the moderate range (Table II). The highest change of wettability in contact with pure terpolymer $\left(\theta \approx 100^{\circ}\right)$ was observed for composite containing $\mathrm{SCF}(\mathrm{FF} 4)\left(\theta \approx 87^{\circ}\right)$. In the case of composites containing SWCNT and carbon fabric the wettability of their surface was on the same level in comparison with terpolymer sample (for SF4 $\theta \approx 105^{\circ}$, for CF63 $\theta \approx 100^{\circ}$ ). It could be the result of the hydrophobic nature of carbon nanotubes and thicker layer of the terpolymer on the surface of the composites containing carbon fabric (CF63). The free surface energy remained on the same level for all investigated composites and for pure terpolymer (Table II). The same relationship was observed for dispersive component of the investigated samples. The unchanging parameters of the free surface energy and dispersion component of surface energy observed for all kinds of samples indicated that the increase hydrophility for composite containing SCF was caused mainly by altered roughness of the surface.

The biggest differentiation was observed for the polar component of investigation samples. This parameter was on the same level of both composites containing SWCNT (SF4) and SCF (FF4) (for SF4 $\gamma_{\mathrm{p}}=0.7 \mathrm{mN} / \mathrm{m}$, for FF4 $\gamma_{\mathrm{p}}=0.4 \mathrm{mN} / \mathrm{m}$ ) while for the terpolymer and the composite containing CFb-r (CF63) was higher, $\gamma_{\mathrm{p}}=1.5 \mathrm{mN} / \mathrm{m}$ and $\gamma_{\mathrm{p}}=3.1 \mathrm{mN} / \mathrm{m}$, respectively. Exposed fibres with chemical group such as hydroxyl $(-\mathrm{OH})$ and carbonyl $(\mathrm{C}=\mathrm{O})$ bonds in $\mathrm{CF}-\mathrm{r}$ composites changed chemical state of the surface which was revealed by a change of the surface free energy. 
TABLE II

Contact angle and surface energy of terpolymer and composites samples.

\begin{tabular}{c|c|c|c|c}
\hline \hline Material & $\begin{array}{c}\text { Water } \\
\text { contact } \\
\text { angle }\left[{ }^{\circ}\right]\end{array}$ & $\begin{array}{c}\text { Surface } \\
\text { energy } \gamma \\
{[\mathrm{mN} / \mathrm{m}]}\end{array}$ & $\begin{array}{c}\text { Surface energy } \\
\text { (polar component) } \\
\gamma_{\mathrm{p}}[\mathrm{mN} / \mathrm{m}]\end{array}$ & $\begin{array}{c}\text { Surface energy } \\
\text { (dispersion component) } \\
\gamma_{\mathrm{d}}[\mathrm{mN} / \mathrm{m}]\end{array}$ \\
\hline terpolymer & $100.0 \pm 3.9$ & $22.6 \pm 0.6$ & $1.5 \pm 0.1$ & $21.2 \pm 0.5$ \\
SF4 & $105.0 \pm 2.1$ & $21.1 \pm 0.4$ & $0.7 \pm 0.04$ & $20.5 \pm 0.4$ \\
FF4 & $87.2 \pm 2.5$ & $24.0 \pm 0.8$ & $0.4 \pm 0.07$ & $23.6 \pm 0.7$ \\
CF63 & $100.4 \pm 3.6$ & $23.1 \pm 0.7$ & $3.1 \pm 0.2$ & $20.0 \pm 0.5$
\end{tabular}

However, not only wettability and free surface energy, but also roughness is responsible for adhesion and spreading of bone cells. Surface of the composite materials alters with the form of the introduced carbon phase. Surface of the pure polymer was smooth (the mean roughness level $R_{\mathrm{a}}=0.20 \mu \mathrm{m}$ ) but introduction of the carbon phase increased its roughness. Exposition of SCF on the surface led to fourteenfold increase of $R_{\mathrm{a}}$ whereas CFb-r in polymer matrices (CF63) increase $R_{\mathrm{a}}$ about fifteen times. The presence of SWCNTs in the polymer matrix increased five times its mean roughness level (Fig. 4).

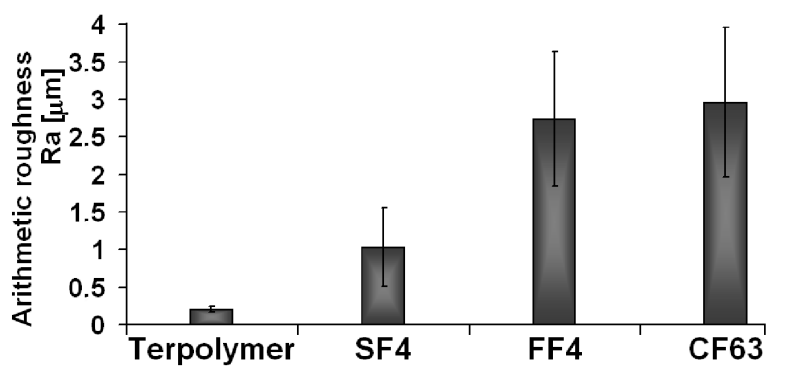

Fig. 4. Arithmetic roughness of polymer and composite samples.

The results indicated that the choice of a carbon phase enables to control the composite surface topography both at micro- and nanolevel.

The presence of modifying phase in the form of SCF and SWCNT in the polymer matrix influenced biological properties of the composites in comparison to the pure terpolymer sample. Degree of proliferation of MG63 cells in the contact with the composites containing both single-walled carbon nanotubes (SF4) and short carbon fibers (FF4) after 7 days of culture was higher of about $60 \%$ comparing to the pure terpolymer (Fig. 5). The highest proliferation was observed for the control sample (polystyrene - PS).

The presence of the carbon phase in the polymer composites led also to better adhesion of cells, and in turn better spreading of bone cells than in the case of the pure polymer. This effect was confirmed by fluorescent microscopy which showed differences in shape, size of cells in contact with SCF and SWCNT composites and with

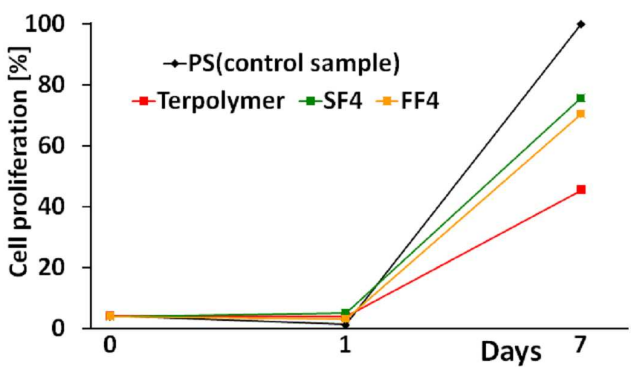

Fig. 5. Cell proliferation in contact with polymer and composites surface.

the pure terpolymer (Figs. 6-9), and also by quantitative analysis.

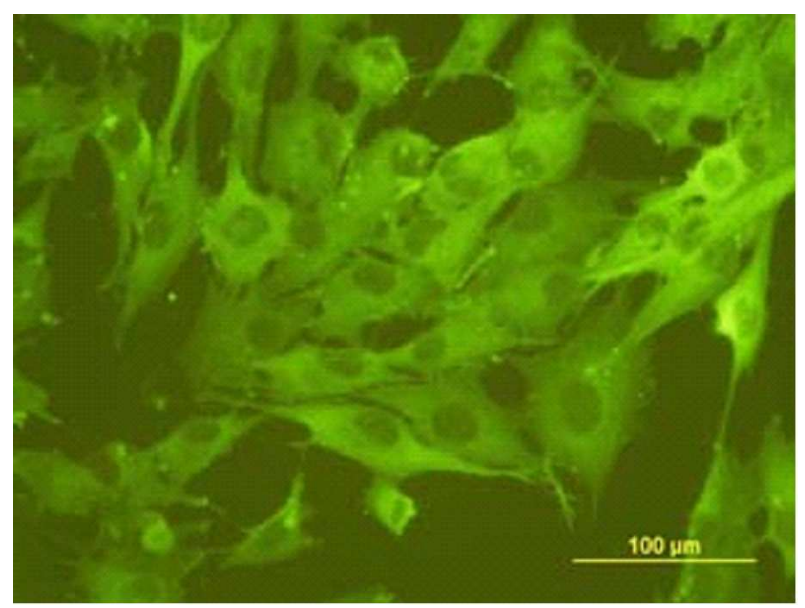

Fig. 6. Immunofluorescence staining of $\beta$-actin in osteoblast-like MG 63 cells on day 3 after seeding on PS.

The cells spreading on the surface of materials containing carbon fillers are much higher in comparison with the pure terpolymer sample where cells were spindle-shaped. The shape of osteoblast cells was comparable with cells in contact with a control sample (PS) (Fig. 6). Moreover, the osteoblast-like cells contain a lot of connections between each other which testifies their good condition in contact with composites containing carbon modifiers. 


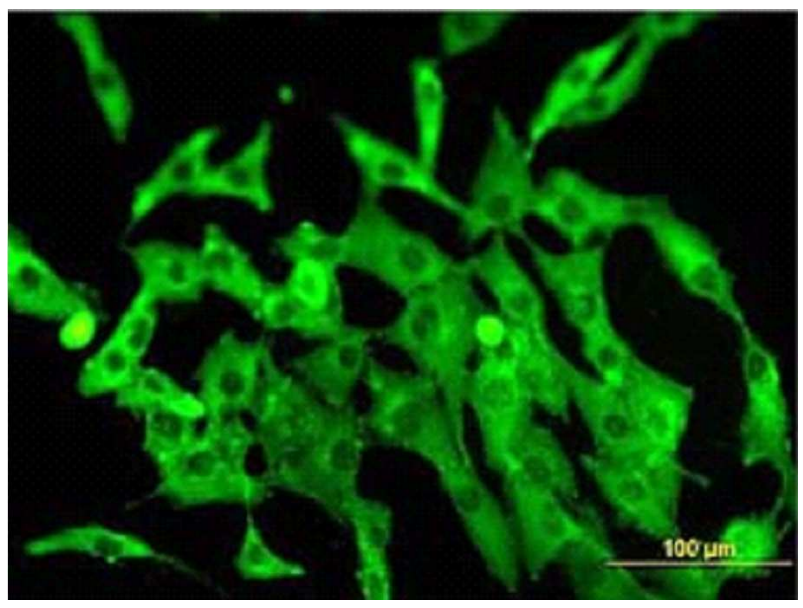

Fig. 7. Immunofluorescence staining of $\beta$-actin in osteoblast-like MG 63 cells on day 3 after seeding on terpolymer.

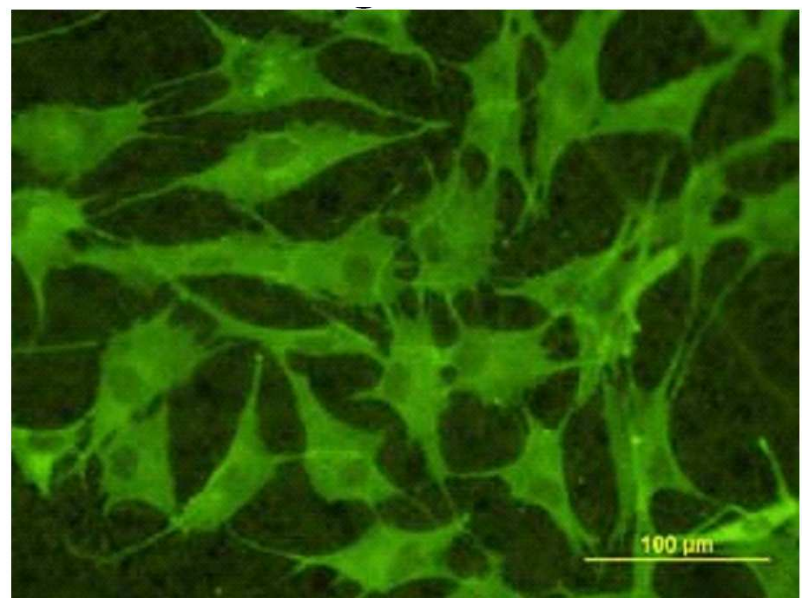

Fig. 8. Immunofluorescence staining of $\beta$-actin in osteoblast-like MG 63 cells on day 3 after seeding on SF4.

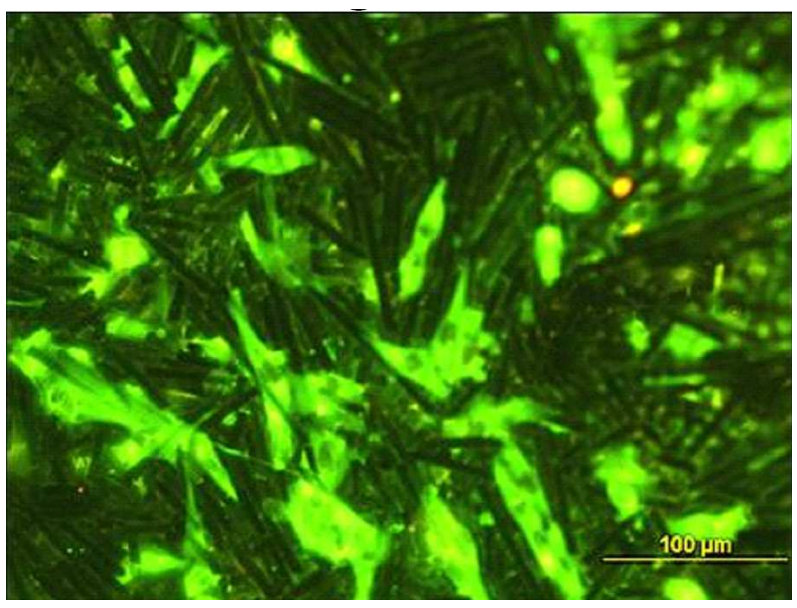

Fig. 9. Imunofluorescence staining of $\beta$-actin in osteoblast-like MG 63 cells on day 3 after seeding on FF4.
The quantitative analysis was performed by means of ELISA test which consisted of determination of concentration of adhesive proteins such as viculine and $\beta$-actine which are responsible for range of interaction between a cell and a material. The highest concentration of viculine (components of focal adhesion plaques) was observed in the case of the composite containing SWCNT (SF4), which was higher than ca. $56 \%$ comparing to the pure terpolymer.

The total area of the surface occupied by adhesive protein $\beta$-actine in the contact with the composite containing SCF (FF4) was about $80 \%$ higher than for pure terpolymer, while for the composite containing carbon fabric (CF63) this parameter was higher by about $13 \%$ (Table III).

\section{TABLE III}

Cells area in contact with surface of samples.

\begin{tabular}{c|c|c|c|c}
\hline \hline & PS & Terpolymer & FF4 & CF63 \\
\hline $\begin{array}{c}\text { Cells area } \\
{\left[\mu \mathrm{m}^{2}\right]}\end{array}$ & $1976 \pm 317$ & $902 \pm 93$ & $1655 \pm 86$ & $1025 \pm 86$
\end{tabular}

This result as well as the result indicating the presence of viculine in the case of the composites containing SWCNTs indicated better adhesion of bone cells to the composites surface than to the pure terpolymer surface. Thus, the observed increase of adhesion, proliferation and viability of the cells in the contact with the composite surface was strongly influenced by physico-chemical properties of the investigated materials. The main factor influencing biological properties of the composites containing SWCNTs and SCFs was their surface roughness, which was higher than of the pure terpolymer. Similarly, in the case of composite containing carbon fabric (CF63) the main influence on cells growth was exerted by a change of the surface topography of the composite comparing to the pure terpolymer sample, and arrangement of the fibers in the polymer matrix causing cells to adhere along the fibers (Fig. 10A and B).

In contact with FF4 and SF4 composite surface the osteoblast cells are located randomly similar like for pure polymer samples (Figs. 11-13). However, for terpolymer sample the number of cells was significantly lower than for composites containing the carbon additives.

Another factor which influenced the cells proliferation and adhesion in contact with all kinds of carbon composites is electrical conductivity. The electrical properties of the composites could stimulate the osteoblast cells growth $[22,23]$.

\section{Conclusions}

The results of investigations on composite materials modified with carbon micro- and nano-additives indicate that these materials are a group of perspective structural biomaterials to which belong also conventional composites of 1D, 2D, 3D-type and multi dispersion (MD). 


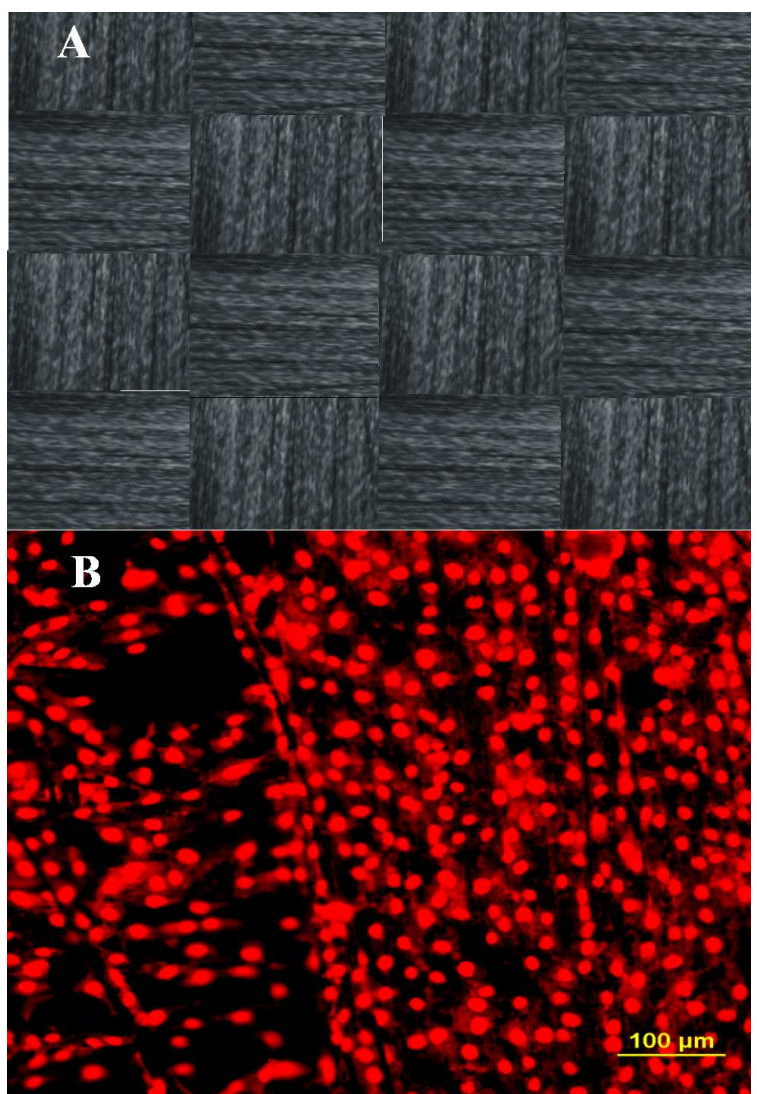

Fig. 10. (A) The surface of CF63 composite. (B) Propidium iodide staining of osteoblast-like MG 63 cells on day 1 in contact with CF63 composite.

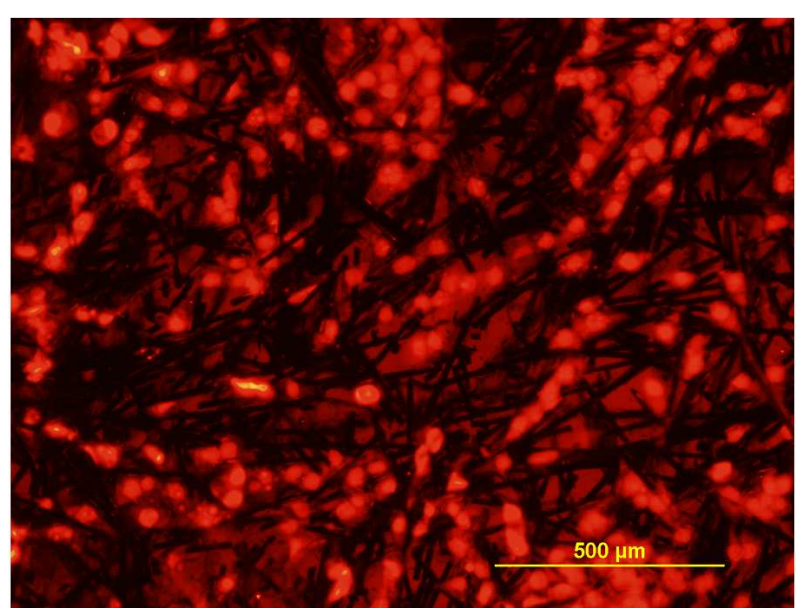

Fig. 11. Propidium iodide staining of osteoblast-like MG 63 cells on day 1 in contact with FF4 composite.

Their usability is determined by mechanical properties i.e. strength, Young's modulus which can be modified in a wide range by choosing the proper form of a fibrous carbon phase (fibers, fabric, cloth). Additionally, the carbon composite materials can be applied to design surface properties of materials for regeneration of damaged

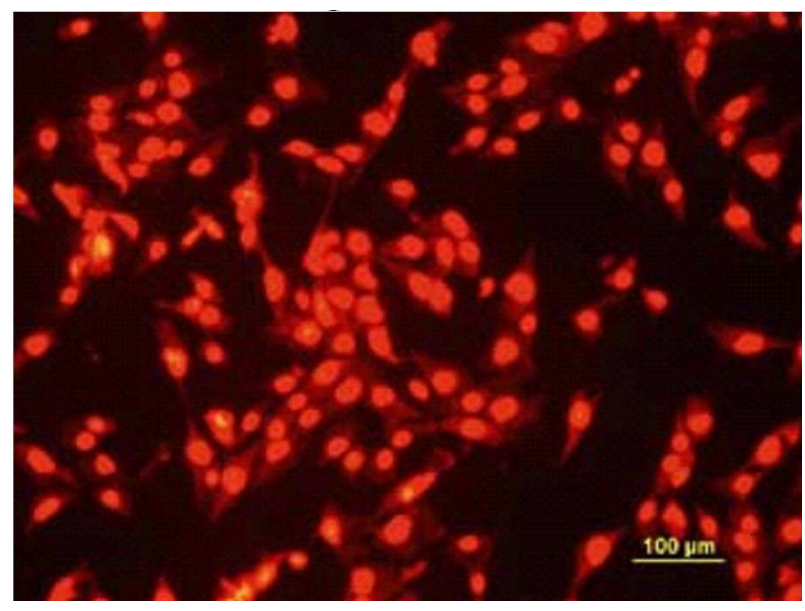

Fig. 12. Propidium iodide staining of osteoblast-like MG 63 cells on day 1 in contact with SF4 composite.

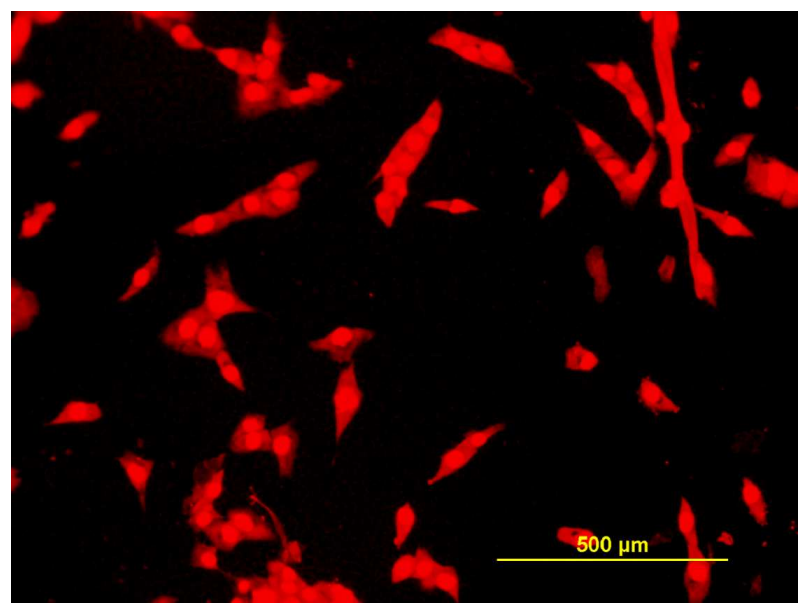

Fig. 13. Propidium iodide staining of osteoblast-like MG 63 cells on day 1 in contact with terpolymer.

bone tissue.

The presence of a carbon phase induces specific roughness and microstructure to composites preserving their good mechanical properties. Carbon nanoparticles in the form of nanotubes and products of carbon fibers fragmentation can be used as phases modifying surface free energy and in a lesser degree the wettability of the material. The results suggest that the biomaterial surface topography, wettability and electrical properties have synergetic effect on osteoblast proliferation and adhesion. The obtained results indicated that composites containing the carbon fillers could be good candidates for controlled regeneration of bone tissue (GBR) implants.

\section{Acknowledgment}

The work was supported by the Ministry of Science and Higher Education, Statute Investigation No. 11.11.160.937. 


\section{References}

[1] M. Blazewicz, European Cells Mater. 2, 21 (2001).

[2] H. Wan, R.L. Williams, P.J. Doherty, D.F. Williams, J. Mater. Sci. Mater. Med. 8, 45 (1997).

[3] M. Blazewicz, S. Blazewicz, C. Wajler, Ceramics Int. 20, (1994)

[4] J.S. Temendoff, A.G. Mikos, Biomaterials 21, 431 (2000).

[5] S. Ramakrishna, J. Mayer, E. Wintermantel, K.W. Leong, Composites Sci. Technol. 61, 1189 (2001).

[6] E. Stodolak, M. Blazewicz, I. Rajzer, L. Grausova, Karbo 4, 187 (2007).

[7] E. Stodolak, V. Ryzner, B. Czajkowska, M. Blazewicz, Eng. Biomater. 61, 12 (2007).

[8] T. Akasaka, F. Watari, Y. Sato, K. Tohji, Mater. Sci. Eng. C 26, 675 (2006).

[9] X. Shi, B. Sitharaman, Q.P. Pham, F. Liang, K. Wu, W.E. Billups, L.J. Wilson, A.G. Mikos, Biomaterials 28, 4078 (2007).

[10] E. Stodolak, A. Wator, D. Woloska-Czapnik, M. Blazewicz, Eng. Biomater. 61, 16 (2007).

[11] M. Blazewicz, C. Paluszkiewicz, J. Mol. Struct. 14, 563 (2001).
[12] W. Kus, A. Gorecki, P. Strzelczyk, P. Swiader, Ann. Transplant 4, 102 (1999).

[13] A. Fraczek, E. Menaszek, C. Paluszkiewicz, M. Blazewicz, Acta Biomater. 4, 1593 (2008).

[14] A. Fraczek, Ph.D. Thesis, University of Science and Technology, Kraków 2009.

[15] C.C. Silva, D. Thomazini, A.G. Pinheiro, N. Aranha, S.D. Figueiro, Mater. Sci. Eng. B 86, 210 (2001).

[16] A. Bouaziz, A. Richert, A. Caprani, Biomaterials 18, 107 (1997).

[17] F. Jianqing, Y. Huipin, Z. Xingdong, Biomaterials 18, 1531 (1997).

[18] Q. Zhang, S. Rastogi, D. Chen, D. Lippits, P.J. Lemstra, Carbon 44, 778 (2006)

[19] D. Klee, Z. Ademovic, A. Bosserhoff, H. Hoecker, G. Mazioolis, Biomaterials 24, 3663 (2003).

[20] M. Morra, C. Della Volpe, J. Biomed. Mater. Res. 42, 473 (1998).

[21] K. Matsuzaka, X. Walboomers, M. Yoshinari, T. Inoue, J. Jansen, Biomaterials 24, 2711 (2003).

[22] L. Zhang, T.J. Webster, Nano Today 4, 66 (2009).

[23] P.R. Supronowicz, P.M. Ajayan, K.R. Ullmann, B.P. Arulanandam, D.W. Metzger, R. Bizios, J. Biomed. Mater. Res. 59, 499 (2002). 